\title{
Terahertz Scanning for Evaluation of Corneal and Scleral Hydration
}

\author{
DOI: $10.17691 / \mathrm{stm} 2018.10 .4 .17$
}

Received February 2, 2018

E.N. Iomdina, DSc, Professor, Chief Researcher ${ }^{1}$;

S.V. Seliverstov, PhD, Senior Lecturer;

A.A. Sianosyan, PhD Student ${ }^{1}$;

K.O. Teplyakova, PhD Student';

A.A. Rusova, Student';

G.N. Goltsman, DSc, Professor, Head of the Department of General and Experimental Physics 2

${ }^{1}$ Moscow Helmholtz Research Institute of Eye Diseases, 14/19 Sadovaya-Chernogryazskaya St., Moscow, 105062, Russia;

${ }^{2}$ Moscow Pedagogical State University, 1/1 Malaya Pirogovskaya St., Moscow, 119991, Russia

The aim of the investigation was to study the prospects of using continuous $\mathrm{THz}$ scanning of the cornea and the sclera to determine water concentration in these tissues and on the basis of the obtained data to develop the experimental installation for monitoring corneal and scleral hydration degree.

Materials and Methods. To evaluate corneal and scleral transmittance and reflectance spectra in the THz range, the developed experimental installations were used to study 3 rabbit corneas and 3 scleras, 2 whole rabbit eyes, and 3 human scleras. Besides, two rabbit eyes were studied in vivo prior to keratorefractive surgery as well as 10 and 21 days following the surgery (LASIK).

Results. There have been created novel experimental installations enabling in vitro evaluation of frequency dependence of corneal and scleral transmittance coefficients and reflectance coefficients on water percentage in the $\mathrm{THz}$ range. Decrease in corneal water content by $1 \%$ was found to lead to reliably established decrease in the reflected signal by $13 \%$. The reflectance spectrum of the whole rabbit eye was measured in the range of $0.13-0.32 \mathrm{THz}$. The study revealed the differences between the indices of rabbit cornea and sclera, as well as rabbit and human sclera.

There was developed a laboratory model of the installation for in vivo evaluation of corneal and scleral hydration using THz radiation.

Conclusion. The preliminary findings show that the proposed technique based on the use of continuous THz radiation can be employed to create a device for noninvasive control of corneal and scleral hydration.

Key words: cornea; sclera; THz radiation; corneal hydration; backward-wave oscillator; avalanche transit-time diode (IMPATT diode).

\section{Introduction}

Water content in biological tissues is crucial for the living organism as a whole and for normal functioning of its individual structures, including the visual organ. The fundamental role of water explains high sensitivity to even a slight water balance impairment that can lead to the development of pathological conditions. Most of the water in the human body is associated with connective tissues able to retain water due to the presence of glycosaminoglycans in the intercellular matrix [1, 2]. The corneoscleral shell of the eye composed of connective tissue normally contains a significant amount of water: normal cornea - about $78 \%$, normal sclera - about $65 \%$ [3]. If excessive water is accumulated in the cornea (corneal edema), its refractive properties change, but what is especially important, the cornea loses its transparence, which significantly reduces visual acuity. On the other hand, dehydration of the cornea leads to changes in its shape and refractive ability, prolonged loss of water resulting in a dystrophic process causing irreversible impairment of visual functions [4].

Corneal water balance impairment can be caused by various eye diseases (corneal inflammation, injury, corneal ectasia, etc.), treatment procedures such as surgical interventions (keratorefractive surgery for myopia and other refractive errors, cross-linking for keratoconus), therapeutic procedures (long-term instillation of certain drugs, in particular, hypotensive medications) or optical techniques (contact lens vision correction) [5].

Sclera performs supporting function for the internal shells (the vascular membrane and the retina) and other eye structures, plays an important role in maintaining the eye shape, therefore, impairment of its biomechanical properties due to dystrophic process in the scleral tissue is the leading cause of myopia progression and development of its disabling complications [6-9].

Corresponding author: Elena N. Iomdina, e-mail: iomdina@mail.ru 
Besides, according to present-day ideas, changes in the structure and properties of the ocular corneoscleral shell prove to be a significant factor in glaucoma development [10-13]. Water balance impairment is supposed to be one of the links in this pathological process.

Thus, adequate control of corneal and scleral hydration is very important for early diagnosing and monitoring the progression of various ophthalmologic pathologies (corneal dystrophy, keratoconus, progressive myopia, primary open-angle glaucoma), identifying indications and contraindications to keratorefractive surgery, selecting effective and safe tactics of local medicament treatment, including tear replacement and hypotensive therapy, and developing an algorithm for contact lens vision correction.

Currently, corneal edema or corneal dystrophy supposedly associated with reduced hydration can be established only indirectly by measuring corneal thickness (topographic pachymetry), determining its outer surface shape (computer-assisted video keratography and corneal mapping) or by measuring the biomechanical parameters of the cornea using the ORA analyzer (Ocular Response Analyzer; ORA Reichert, USA). However, changes in corneal thickness or shape can be associated not only with its impaired hydration but also with other factors, therefore, the existing indirect methods for evaluation of water content in the corneal tissue are not informative enough. Measuring scleral thickness with contact methods such as ultrasound biomicroscopy (in the anterior) or echodensitometry (at the equator and posterior pole of the eye) is also insufficiently accurate and rarely used in clinical practice as an indirect hydration indicator.

At present, there is no direct noncontact method for determining corneal and scleral hydration in the arsenal of a clinical ophthalmologist. The use of electromagnetic radiation of the terahertz $(\mathrm{THz})$ range $(0.3-3.0 \mathrm{THz})$ for this purpose seems to be very promising, since water is known to exhibit high absorption and dielectric permeability in this frequency range, which determines high reflectance coefficient. This provides the possibility of using $\mathrm{THz}$ scanning in the light reflected from biological material surface in order to detect the slightest changes in the concentration of water contained there.

Only a few research groups in the world are involved in developing the system for $\mathrm{THz}$ scanning of biological tissue hydration. Pulse THz sources are mainly used for this purpose. For example, the paper [14] presents a method for $\mathrm{THz}$ scanning of porcine corneal hydration. The authors use a traditional scheme for obtaining pulsed $\mathrm{THz}$ radiation consisting of a photoconductive antenna and pumping femtosecond laser. A detector based on Schottky barrier diode serves as a receiver. This can be replaced in the proposed scheme by more sensitive high-speed detector based on hot-electron bolometer [15]. Other authors employed a similar technique earlier. In particular, the paper [16] presents a $\mathrm{THz}$ imaging system that allows high-precision differentiation of tissue areas with different water content. Other studies have successfully demonstrated the possibility of $\mathrm{THz}$ imaging in diagnosis of cutaneous carcinoma and melanoma and analysis of skin burns based on water concentration measurement [17-20]. The paper [21] presents the results of measuring reflectance coefficient of porcine cornea depending on its hydration in the range of $0.2-1.0 \mathrm{THz}$. The authors have revealed approximate linear dependence of reflectance coefficient on water concentration in the tissue with monotonically decreasing slope coefficient at increasing radiation frequency.

The work of Taylor et al. [22] shows the results of intravital measuring the reflectance coefficient of rabbit cornea using pulse $\mathrm{THz}$ imaging system $(0.47-0.58 \mathrm{THz})$ and a millimeter-wave reflectometer $(100 \mathrm{~Hz})$. Positive correlations between corneal thickness and reflectance in the millimeter wave range have been obtained.

However, the method used in the above works is still difficult to implement in practical devices due to the fact that the implementation of the proposed scheme requires the use of powerful, bulky and extremely expensive femtosecond laser. Besides, these works provide no data on the reflectance and transmittance spectra of tissues in the millimeter wave range (less than $0.3 \mathrm{THz}$ )

A research group from Lomonosov Moscow State University is currently working in the same direction. [23]. These researchers use special material in their investigations: pressed $\mathrm{Al}_{2} \mathrm{O}_{3}$ plates as models of the cornea. This material is characterized by high moisture absorbing ability making it possible to control water content in the material affected by changes in ambient humidity. By varying moisture content in the sample, its transmittance and reflectance coefficients are investigated in the $\mathrm{THz}$ range using time resolution spectrometer. However, it is important to note that this approach is far from being applicable in real practice at this stage as the cornea model developed by the authors is very rough and created with no regard for the internal corneal structure, its use is actually reduced to the analysis of one integral parameter: the average water concentration throughout the sample.

Liu et al. [24] have studied transmittance and reflectance coefficients of the extracted cornea depending on water content. They show that complex dielectric permeability of the cornea monotonically decreases with a decrease in corneal water content. In their investigation, the authors use time-resolution $\mathrm{THz}$ spectrometer with optimized scanning speed. In another work, the same authors evaluate the dependence of corneal transmittance and reflectance coefficients on radiation frequency in the range of $0.1-1.5 \mathrm{THz}$ using time resolution $\mathrm{THz}$ spectroscopy technique in vitro [25]. The results show that reflectance coefficient decreases with increasing radiation frequency, while absorption coefficient, on the contrary, increases almost linearly.

The results obtained so far [26] prove the feasibility 
and prospective value of carrying out research in this direction in order to create an informative method for evaluation of corneal and scleral hydration degree in vivo.

The aim of the investigation was to study transmittance and reflectance spectra of the cornea and the sclera in the $\mathrm{THz}$ frequency range, to evaluate the prospects of using continuous $\mathrm{THz}$ scanning for measuring water concentration in these tissues and on the basis of the obtained data to develop the experimental installation for monitoring corneal and scleral hydration degree.

\section{Materials and Methods}

To evaluate corneal and scleral transmittance and reflectance spectra in $\mathrm{THz}$ range, 3 rabbit corneas and 3 scleras, 2 whole rabbit eyes, and 3 human scleras were studied. Besides, two rabbit eyes were studied in vivo prior to keratorefractive surgery as well as 10 and 21 days following the surgery (LASIK).

The order $\mathrm{No} .199 \mathrm{H}$ "On the Approval of the Rules of Good Laboratory Practice" (Russia, 2016) and the International Guiding Principles for Biomedical Research Involving Animals (CIOMS and ICLAS, 2012) were strictly observed. The work was performed in accordance with the ethical principles established by the European Convention for the Protection of Vertebrate Animals Used for Experimental and Other Scientific Purposes (Strasburg, 2006). The permission from the Ethics Committee of Moscow Helmholtz Research Institute of
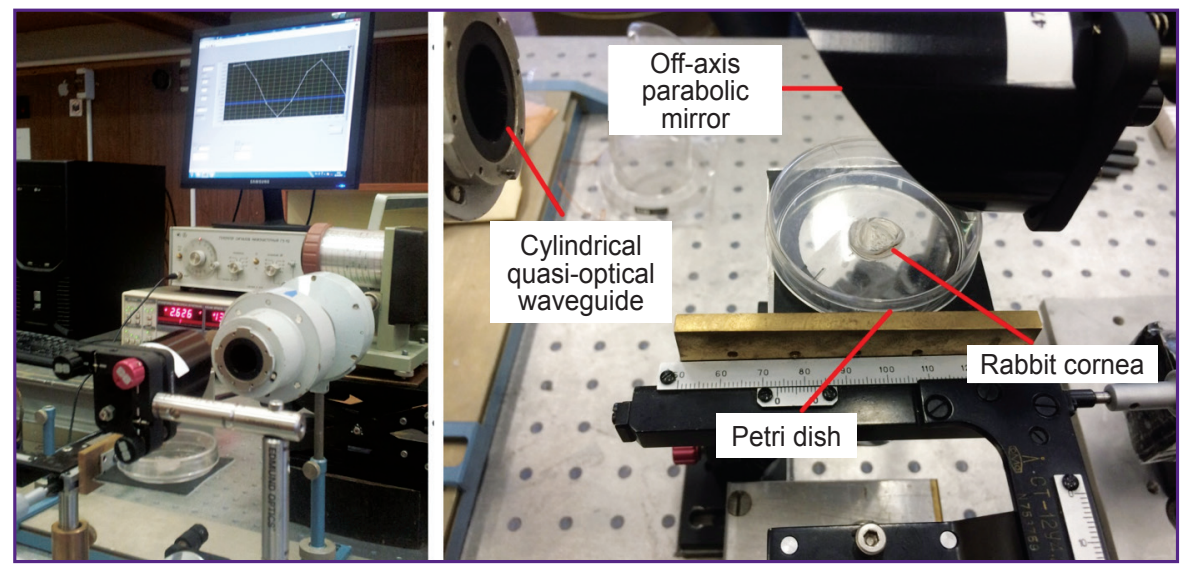

Figure 1. Evaluation of transmittance spectra of corneal samples in the $\mathrm{THz}$ range calibration of the radiation path was performed with a Petri dish, this calibration was taken into account later when transmittance spectra of the material were obtained.

To measure corneal and scleral reflectance coefficients in the $\mathrm{THz}$ range, depending on their water content, there was also created an experimental installation with an avalanche transit time diode (IMPATT diode) of about $95 \mathrm{GHz}$ radiation frequency used as a radiation source. This radiation was directed with a special horn to the investigated sample placed in a Petri dish (Figure 3).

The generated radiation is amplitude-modulated by the power supply unit at the frequency of $16.6 \mathrm{kHz}$. The reflected signal was measured using a detector based on Schottky barrier diode from which the electrical signal is fed to the phase-sensitive detector. The reference signal was fed to the detector from synchronization output of the power supply unit of the IMPATT diode. The second horn was used to match the signal reflected
Eye Diseases to conduct these specific experiments was obtained.

To study corneal and scleral transmittance coefficients in the $\mathrm{THz}$ frequency range, there was created an experimental installation with a programmable generator in the range of $129.2-145.5 \mathrm{GHz}$ and the minimum frequency step of $10 \mathrm{MHz}$ used as a radiation source. The signal was amplitude-modulated by electric squarewave signal from an external sound generator at the frequency of $10 \mathrm{~Hz}$ (Figure 1).

The effective diameter of the beam in the focus of the mirror system was less than $1 \mathrm{~cm}$.

The passed signal was detected using the Golay cell, from which an electric signal was sent to a phasesensitive detector. The reference signal was fed to the detector from synchronization output of the sound generator. Schematic structure of the experimental installation is shown in Figure 2. It is important to note that the radiation power of the employed generator depends significantly on frequency. For this reason, 


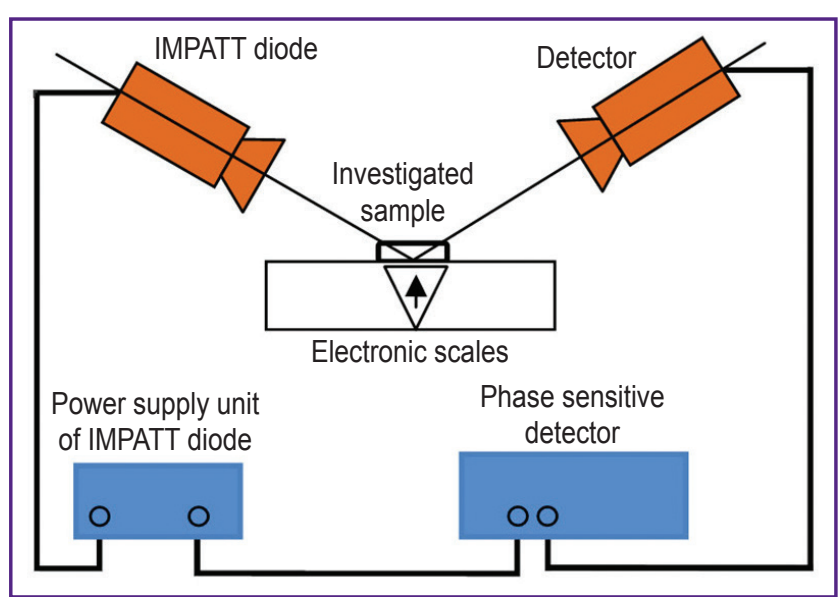

Figure 3. Schematic structure of the experimental installation for measuring corneal and scleral reflectance coefficients in the $\mathrm{THz}$ range, depending on their water content

IMPATT diode - avalanche transit-time diode as a source of radiation

from the tissue under study with the detector. The Petri dish containing the sample was mounted on scales with measurement accuracy of $10^{-4} \mathrm{~g}$. This provided the possibility to measure the dependence of the reflected signal on water content in corneal or scleral sample in dehydration process.

Measurements were taken while the signal kept changing, the original shape of the cornea and the sclera being preserved. Absorbing material was glued to the opposite side of the Petri dish to reduce the parasitic radiation reflection from the metal surface of the scales used in the experiment. However, it appeared to be impossible to get rid of this parasitic reflected radiation completely. In the experiment, it accounted for about $30 \%$ of the total detected power. For this reason, the value of the received reflected signal was expressed in relative units.

\section{Results and Discussion}

The created experimental installations (see Figures 1-3) enabled us to evaluate frequency dependence of transmittance coefficients of rabbit and human cornea and sclera as well as the dependence of reflectance coefficients of these tissues on water percentage in the $\mathrm{THz}$ frequency range.

As we can see from the presented diagrams (Figure 4), transmittance coefficients of corneal and scleral samples expectedly increased while drying, since the content of unbound water being the main absorber of $\mathrm{THz}$ frequency range radiation decreased in the tissues under study.

However, alternating transmittance peaks spaced by about $1 \mathrm{GHz}$ frequency were clearly visible in the corneal transmittance spectrum in the $\mathrm{THz}$ range, their origin has yet to be investigated in more detail in the future.

Similar measurements were performed for human sclera (Figure 5).

The study showed that water percentage decrease in rabbit cornea by $1 \%$ leads to reliably established decrease in the reflected signal by $13 \%$ (Figure 6), which is consistent with the results presented in paper [21].

Linear dependence of reflectance coefficient on water percentage in the corneal area with weak dehydration was also confirmed. Stronger dehydration led to changes in the curve shape, which was most likely due to corneal deformation caused by water loss.

The main disadvantage of the setup used to study reflectance coefficient was the fact that reflection from

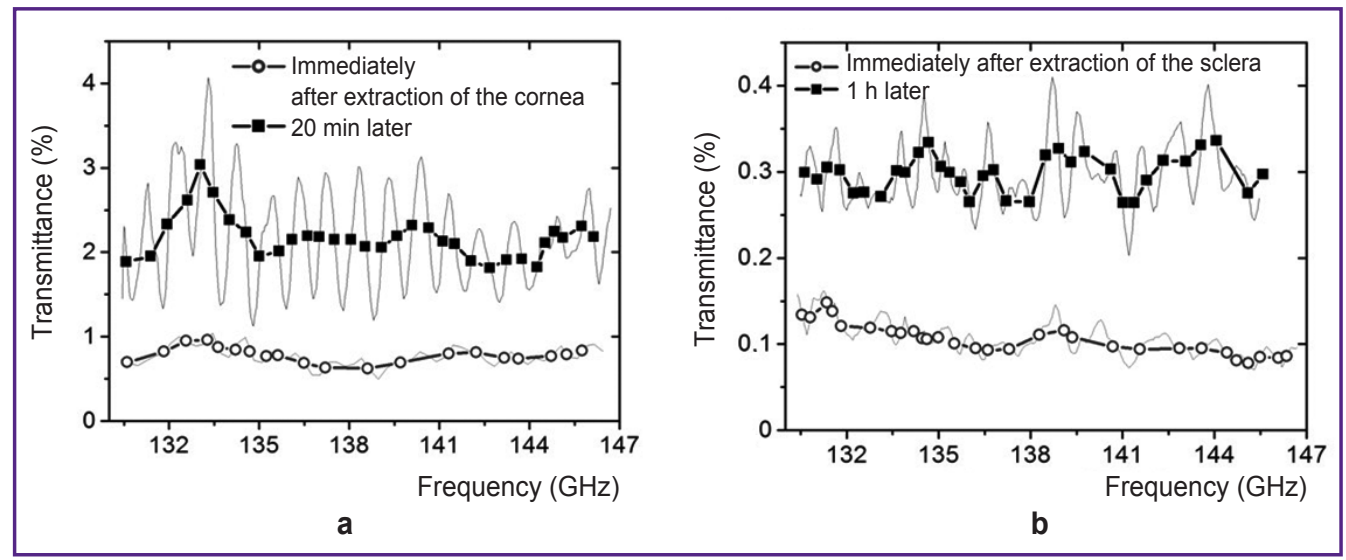

Figure 4. THz radiation transmittance spectra:

(a) of rabbit cornea; (b) of rabbit sclera. In both cases, the curve with empty round markers corresponds to the transmittance spectrum of the material immediately after its extraction from the rabbit eye, the curve with black square markers shows the findings obtained some time later (about $20 \mathrm{~min}$ for the cornea, about $1 \mathrm{~h}$ for the sclera) when certain amount of water has evaporated from the tissue 


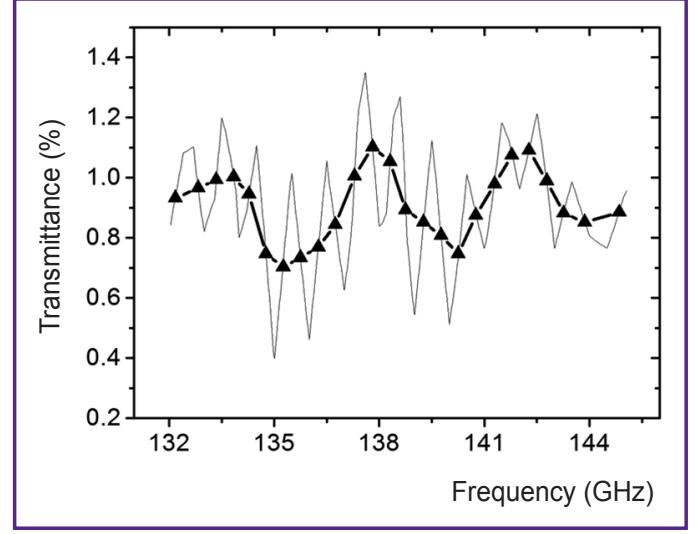

Figure 5. Transmittance spectrum of human sclera in the $\mathrm{THz}$ frequency range

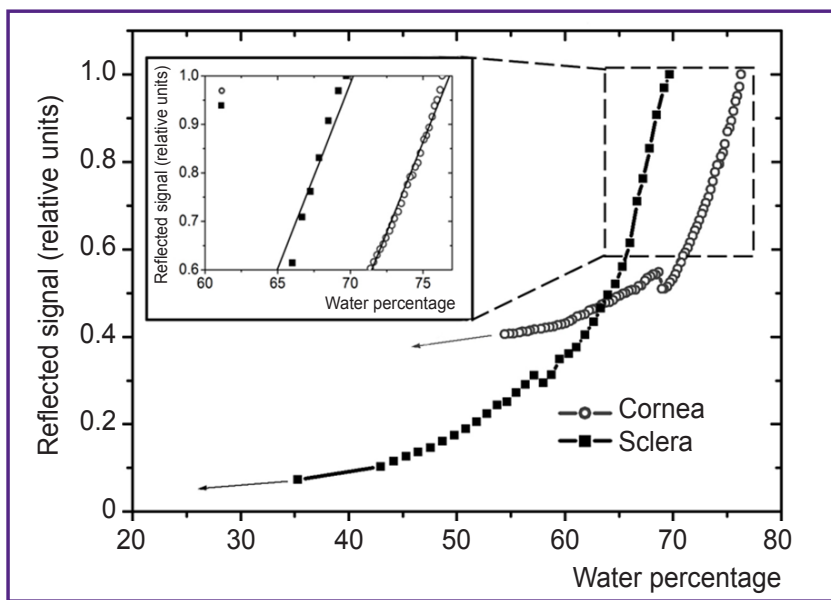

Figure 6 . The diagram of reflected signal dependence on water percentage:

in rabbit cornea (a curve with empty round markers); in rabbit sclera (a curve with black square markers)

the tissue surface was measured integrally. Therefore, it was impossible to study reflection from the whole eye as most of incident radiation was scattered due to eye sphericity and the power reaching the detector was insufficient for reliable registration. For this reason, in the experiment on evaluation of corneal reflectance spectrum in $0.13-0.32 \mathrm{THz}$ range with the whole eye, we directed radiation produced by a generator with a backward-wave oscillator to the eye from an open 2-mm waveguide placed in the immediate vicinity of the corneal surface and recorded scattered reflected radiation. Calibration was performed based on radiation reflected from the metal plate. The results of the experiment on evaluation of whole rabbit eye reflectance spectrum in $0.13-0.32 \mathrm{THz}$ range are shown in Figure 7 .

The results seem to be promising with regard to the possibility of developing a device for noninvasive control of corneal and scleral hydration degree in clinical practice.
So far, there has been developed an experimental installation (laboratory model) for in vivo evaluation of corneal reflectance coefficient in laboratory animals (rabbits) in the THz range (Figure 8). IMPATT diode with $95 \mathrm{GHz}$ frequency is used in this installation as a source of $\mathrm{THz}$ radiation. Radiation from the source is directed to the rabbit cornea using a quasi-optical horn (Figure 9). The power of scattered radiation reflected from the eye and modulated with a mechanical obturator is measured with the Golay cell, from which an electric signal is fed to a lock-in amplifier.

It should be noted, living rabbits were used in our work in conditions close to real practice in contrast to the study [23] performed on a model of the cornea (plates of pressed material $\mathrm{Al}_{2} \mathrm{O}_{3}$ ).

This installation was employed to study temporal dynamics of reflectance coefficient of rabbit cornea in the $\mathrm{THz}$ range before and after (days 10 and 21) keratorefractive surgery (LASIK) was performed. The results showed that the coefficient values increased with each subsequent postoperative measurement for all examined rabbit eyes, which may be due to structural changes in the cornea caused by surgery as well as

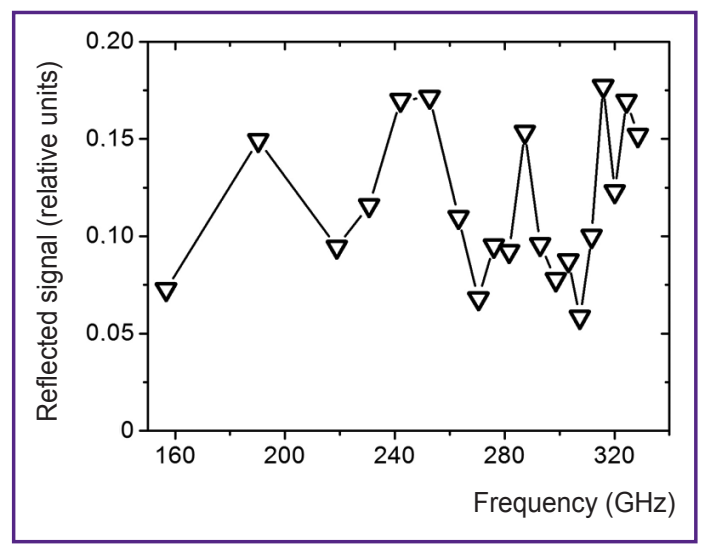

Figure 7. Reflectance spectrum of whole rabbit eye in the $\mathrm{THz}$ range

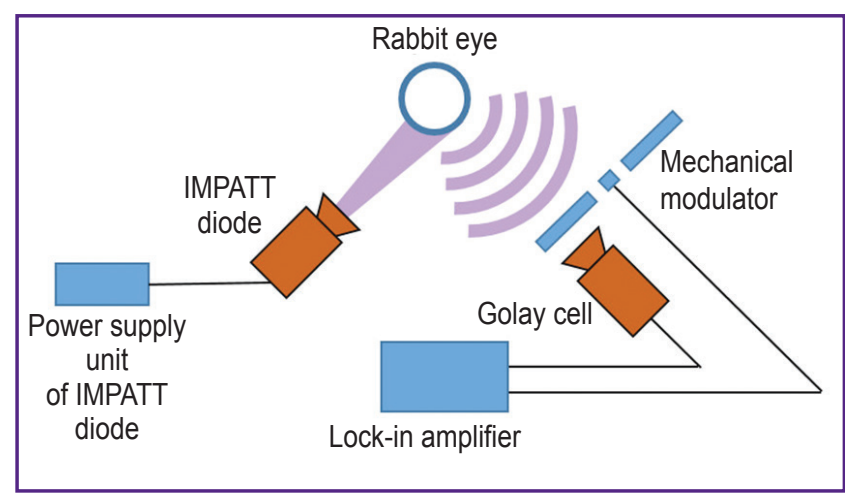

Figure 8. Principle diagram of the experimental installation for in vivo evaluation of rabbit corneal reflectance coefficient in the $\mathrm{THz}$ range with avalanche transit-time diode (IMPATT diode) as source of radiation 


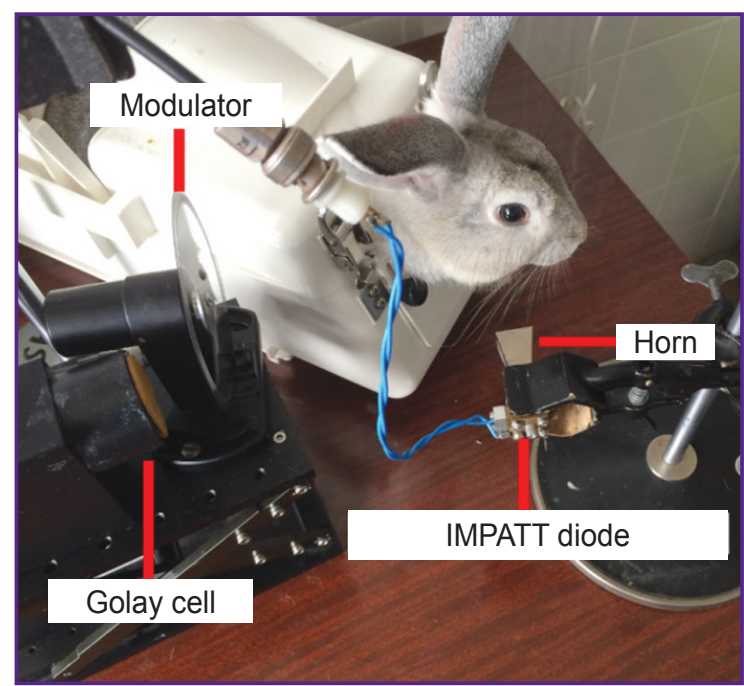

Figure 9. Part of the experimental installation for in vivo evaluation of rabbit corneal reflectance coefficient in the $\mathrm{THz}$ range

changes in corneal water balance. It is important to note, however, measurement of reflectance coefficient using the developed installation has a large error and requires further optimization of its operation in terms of matching incident radiation to the eye and the reflected radiation to the detector.

\section{Conclusion}

There have been created novel experimental installations for in vitro evaluation of frequency dependence of corneal and scleral transmittance coefficients and reflectance coefficients on water percentage in the $\mathrm{THz}$ range. The installations provide the possibility to measure reflectance spectrum of the whole rabbit eye in the range of $0.13-0.32 \mathrm{THz}$. Corneal and scleral transmittance spectra have been obtained and dependence of corneal and scleral reflectance coefficients on water percentage has been evaluated. The study revealed the differences between the indices of rabbit cornea and sclera as well as rabbit and human sclera. There has been developed a laboratory model of the installation for in vivo evaluation of corneal and scleral hydration using $\mathrm{THz}$ radiation. The preliminary findings show that the proposed technique based on the use of continuous $\mathrm{THz}$ radiation can be employed in prospect for noninvasive control of corneal and scleral hydration.

Study funding. The research has been carried out with the support of the Russian Science Foundation (project No.17-72-30036).

Conflict of interests. The authors declare that materials or methods used in the study do not involve conflicting interests.

\section{References}

1. Serov V.V., Shekhter A.B. Soedinitel'naya tkan' (funktsional'naya morfologiya $i$ obshchaya patologiya) [Connective tissue (functional morphology and general pathology)]. Moscow: Meditsina; 1981.

2. International review of connective tissue research. Vol. 10. Edited by Hall D.A., Jackson D.S. Elsevier; 2013.

3. Fatt I., Weissman B.A. Physiology of the eye: an introduction to the vegetative functions. ButterworthHeinemann; 2013.

4. Vanmeter W.S., Lee W.B., Katz D.G. Corneal edema. In: Tasman W., Jaeger E.A. (editors). Duane's Ophthalmology. Vol. 4. Philadelphia, PA: Lippincott Williams \& Wilkins; 2013.

5. Lim G.C., Lin H.C., Shen S.C., Lin K.K. Toxic keratopathy-related corneal dehydration after laser in situ keratomileusis. J Cataract Refract Surg 2005; 31(8): 16561658, https://doi.org/10.1016/j.jcrs.2005.01.020.

6. Iomdina E.N. Biomekhanicheskie i biokhimicheskie narusheniya sklery pri progressiruyushchey blizorukosti i metody ikh korrektsii. V kn.: Zritel'nye funktsii i ikh korrektsiya $u$ detey [Biomechanical and biochemical disorders of sclera in progressive myopia and methods of their correction. In: Visual functions and their correction in children]. Pod red. Avetisova S.E., Kashchenko T.P., Shamshinovoy A.M. [Avetisov S.E., Kashchenko T.P., Shamshinova A.M. (editors)]. Moscow: Meditsina; 2005; p. 163-183.

7. Iomdina E.M., Tarutta E.P. Modern trends of basic research in pathogenesis of progressive myopia. Vestnik Rossiyskoy akademii meditsinskikh nauk 2014; 69(3-4): 44-49.

8. McBrien N.A., Gentle A. Role of the sclera in the development and pathological complications of myopia. Prog Retin Eye Res 2003; 22(3): 307-338, https://doi.org/10.1016/ s1350-9462(02)00063-0.

9. Rada J.A.S., Shelton S., Norton T.T. The sclera and myopia. Exp Eye Res 2006; 82(2): 185-200, https://doi. org/10.1016/j.exer.2005.08.009.

10. Iomdina E.N., Ignatieva N.U., Danilov N.A., Arutunyan L.L., Kiseleva O.A., Nazarenko L.A. Biochemical, structural and biomechanical features of human scleral matrix in primary open-angle glaucoma. Vestnik oftal'mologii 2011; 127(6): 10-14.

11. Iomdina E.N., Bauer S.M., Kotlyar K.E. Biomekhanika glaza: teoreticheskie aspekty i klinicheskie prilozheniya [Biomechanics of the eye: theoretical aspects and clinical applications]. Moscow: Real Taym; 2015.

12. Danilov N.A., Ignatieva N.Y., Grokhovskaya T.E., Lunin V.V., Iomdina E.N., Arutyunyan L.L. Sclera of the glaucomatous eye: physicochemical analysis. Biophysics 2011; 56(3): 490-495, https://doi.org/10.1134/s0006350911030067.

13. Coudrillier B., Tian J., Alexander S., Myers K.M., Quigley H.A., Nguyen T.D. Biomechanics of the human posterior sclera: age- and glaucoma-related changes measured using inflation testing. Invest Ophthalmol Vis Sci 2012; 53(4): 1714-1728, https://doi.org/10.1167/iovs.11-8009.

14. Singh R.S., Tewari P., Bourges J.L., Hubschman J.P., Bennett D.B., Taylor Z.D., Lee H., Brown E.R., Grundfest W.S., Culjat M.O. Terahertz sensing of corneal hydration. Conf Proc IEEE Eng Med Biol Soc 2010; 2010: 3021-3024, https://doi. org/10.1109/iembs.2010.5626146.

15. Seliverstov S., Maslennikov S., Ryabchun S., Finkel M., Klapwijk T.M., Kaurova N., Smirnov Y., Voronov B., Gol'tsman G. Fast and sensitive terahertz direct detector based 
on superconducting antenna-coupled hot electron bolometer. IEEE Trans Appl Supercond 2015; 25(3): 1-4, https://doi. org/10.1109/tasc.2014.2372171.

16. Taylor Z.D., Singh R.S., Culjat M.O., Suen J.Y., Grundfest W.S., Brown E.R. THz imaging based on waterconcentration contrast. In: Jensen J.O., Cui H.-L., Woolard D.L., Hwu R.J. (editors). Terahertz for military and security applications VI. SPIE; 2008, https://doi.org/10.1117/12.785337.

17. Wallace V.P., Fitzgerald A.J., Shankar S., Flanagan N., Pye R., Cluff J., Arnone D.D. Terahertz pulsed imaging of basal cell carcinoma ex vivo and in vivo. Br J Dermatol 2004; 151(2): 424-432, https://doi.org/10.1111/j.1365-2133.2004.06129.x.

18. Dougherty J.P., Jubic G.D., Kiser W.L. Jr. Terahertz imaging of burned tissue. In: Linden K.J., Sadwick L.P. (editors). Terahertz and gigahertz electronics and photonics VI. SPIE; 2007, https://doi.org/10.1117/12.705137.

19. Sensing with terahertz radiation. Springer series in optical sciences. Mittleman D. (editor). Springer Berlin Heidelberg; 2003; https://doi.org/10.1007/978-3-540-45601-8.

20. Bajwa N., Au J., Jarrahy R., Sung S., Fishbein M.C., Riopelle D., Ennis D.B., Aghaloo T., St John M.A., Grundfest W.S., Taylor Z.D. Non-invasive terahertz imaging of tissue water content for flap viability assessment. Biomed Opt Express 2017; 8(1): 460-474, https://doi.org/10.1364/ boe.8.000460.

21. Bennett D.B., Taylor Z.D., Tewari P., Singh R.S., Culjat M.O., Grundfest W.S., Sassoon D.J., Johnson R.D., Hubschman J.P., Brown E.R. Terahertz sensing in corneal tissues. J Biomed Opt 2011; 16(5): 057003, https://doi. org/10.1117/1.3575168.

22. Taylor Z.D., Garritano J., Sung S., Bajwa N., Bennett D.B., Nowroozi B., Tewari P., Sayre J.W., Hubschman J.-P., Deng S.X., Brown E.R., Grundfest W.S. $\mathrm{THz}$ and $\mathrm{mm}$-wave sensing of corneal tissue water content: in vivo sensing and imaging results. IEEE Trans Terahertz Sci Technol 2015; 5(2): 184-196, https://doi.org/10.1109/ tthz.2015.2392628.

23. Nazarov M.M., Shkurinov A.P., Cherkasova O.P. Study of the dielectric function of aqueous solutions of glucose and albumin by $\mathrm{THz}$ time-domain spectroscopy. Quantum Electronics 2016; 46(6): 488-495, https://doi.org/10.1070/qel16107.

24. Liu W.-Q., Lu Y.-F., Jiao G.-H., Chen X.-F., Zhou Z.-S., She R.-B., Li J.-Y., Chen S.-H., Dong Y.-M., LV J.-C. Spectroscopic measurements and terahertz imaging of the cornea using a rapid scanning terahertz time domain spectrometer. Chinese Physics B 2016; 25(6): 060702, https:// doi.org/10.1088/1674-1056/25/6/060702.

25. Liu W.-Q., Lu Y.-F., Jiao G.-H., Chen X.-F., Li J.-Y., Chen S.-H., Dong Y.-M., Lv J.-C. Terahertz optical properties of the cornea. Optics Communications 2016; 359: 344-348, https://doi.org/10.1016/j.optcom.2015.09.107.

26. Iomdina E.N., Goltsman G.N., Seliverstov S.V., Sianosyan A.A., Teplyakova K.O., Rusova A.A. Study of transmittance and reflectance spectra of the cornea and the sclera in the THz frequency range. J Biomed Opt 2016; 21(9): 097002, https://doi.org/10.1117/1.jbo.21.9.097002. 